\title{
Subsurface tectonic characterizations by the use of geo-electrical resistivity technique and their implications on environmental soil and groundwater at Erbil dumpsite, west of Erbil city - Iraqi Kurdistan region
}

\author{
Sirwa Qader Smail GARDI ${ }^{1, *}$, Jamal ASFAHANI ${ }^{2}$ \\ ${ }^{1}$ Department of Geology, College of Science, University of Salahaddin, \\ Erbil, Kurdistan Region, Iraq \\ ${ }^{2}$ Department of Geology, Atomic Energy Commission of Syria, \\ P. O. Box 6091, Damascus, Syria
}

\begin{abstract}
Twenty seven vertical electrical resistivity soundings (VES), distributed on three profiles, have been carried out around the Erbil city dumpsite location in northern Iraq, by using Schlumberger configuration. The main objective of those VES soundings is to characterize the subsurface structures and to detect the probable soil contamination zones at the dumpsite and the surrounding district. Bai Hassan aquifer in the study region is one of most important natural fresh water in the central sub-basin of Erbil. The 2D Pichgin and Habibulleav technique is applied herein to study and analyse the three VES profiles. Its application in the study region has highly demonstrated the efficacy of such a technique. In fact, the subsurface structures in the study area have been recognized, and the exact position, dip, direction of the faults and groundwater level were also precisely detected. The role of applying this technique together with the available geological information, while carrying out geo-electrical surveys is emphasized to obtain useful, cheap and fast lithological, groundwater table and structural subsurface information.
\end{abstract}

Key words: VES, Schlumberger, Pichgen and Habibullaev, tectonic, soil, groundwater, dumpsite, Erbil

\section{Introduction}

Electrical resistivity investigation techniques are widely used for water exploration, to quickly and economically obtain details about the location,

\footnotetext{
*corresponding author: e-mail: sirwagardi@gmail.com
} 
depth and resistivity of subsurface formations. Those techniques through making suitable measurements on the surface proved to be very successful in delineating the subsurface geology and structures (Olasehinde et al., 2013). Electrical Resistivity techniques are extensively used in the search for suitable groundwater sources, to monitor types of groundwater pollution, in engineering surveys to locate sub-surface cavities, faults and fissures, permafrost, etc., in archaeology for mapping out the areal extent of remnants of buried formations of ancient buildings, amongst many other applications (Reynolds, 2011).

The most effective electrical resistivity surveys for groundwater exploration were carried out by applying the traditional Vertical Electrical Sounding (VES), with Schlumberger configuration (Edwards, 1977; Zohdy et al., 1984).

The geo-electrical survey has been carried out in the study area to mainly give information concerning the thickness of subsurface layers, geological structures, contributing the groundwater occurrence, lateral and vertical variations of subsurface layers and finally to delineate the contaminated zones which are affected by the wastewater valley.

The study area is characterized by a good potential of groundwater and soil resources. Bai Hassan Formation (formerly Upper Bakhtiari) represents the main water bearing formation in the area. The wastewater valley exists at a lowland area. There is therefore a risk of the soil and wastewater flow to the neighbouring cultivated lands. The wastewater flow may contaminate the shallow subsurface soil. The leakage of water into the underground aquifer also represents serious threats for the population totally dependent on groundwater in this area. The presence of an impermeable layer such as clays fortunately prevents the leakage of wastewater into the underground fresh water aquifer.

The present paper is an important application contribution of the geoelectrical survey together with the use of Schlumberger VES technique, oriented towards clarifying the subsurface structure in the study area, and its implications on environmental aspects (soil and groundwater). The measured VES distributed on three main profiles in the study region, have been integrally qualitatively and quantitatively (in 1D and 2D) interpreted to get the maximum that enable us completing the subsurface pictures for those three profile sections. 
The 1D quantitative interpretations aimed at knowing the real resistivities and thicknesses under every studied VES (Zohdy and Bisdorf, 1989). The 2D quantitative interpretations include mainly the application of Pichgin and Habibulleav (1985) method, enhanced by Asfahani and Radwan (2007). This technique has been successfully applied in Syria for solving different structural subsurface problems related to the groundwater (Asfahani and Radwan, 2007), and geo-exploration mining such as phosphate, uranium, sulphur and bitumen (Asfahani, 2011). More recently, Al-Fares and Asfahani (2018) efficiently applied this 2D technique for solving Abou Barra leakage dam problem in northern Syria, where the results obtained by this technique agree well with those obtained by $2 \mathrm{D}$ resistivity tomography.

The 2D Pichgin and Habibulleav (1985) technique is considered as the most sophisticated one in determining the subsurface and structural features and oblique contacts between different types of rocks (Asfahani, 2011). By using this technique, the interpretation is carried out along a given profile, where a number of VES are distributed along an oriented line.

The traditional 2D interpretations of several VES distributed along a given profile are incapable to give an accurate and integrated subsurface picture. Such a weakness is due to the fact that every VES point is 1D interpreted without considering the effect of other surrounding VES.

The advantages of 2D Pichgin and Habibulleav (1985) technique are related to the fact that all the values (resistivity as a function of $A B / 2$ ) of the VES distributed along a given profile are taken into consideration laterally (along the profile) and vertically. This strengthens the interpretation and allows us to determine the subsurface structures and the main tectonic features in the study area.

According to this technique, the non-homogeneity points are laterally and vertically determined, where the analysis of their variations allows determining the main structural features along the studied profile. The results of the quantitative 1D for every interpreted VES existing along the studied profile (True Resistivity and thicknesses) are superimposed on the resulted map of non-homogeneity points. This procedure finally allows getting the complete 2D lithological subsurface model for the study profile.

The main objectives of this paper are therefore constructed to be included (1) carrying out geo-electrical survey in the study area with VES Schlumberger array, (2) interpreting the measured VES points with 1D to 
get the real subsurface layers (thickness and resistivity) for every measured VES point in this area, (3) interpreting the VES distributed along a given profile with 2D quantitative interpretation (Pichgin and Habibulleav, 1985), (4) determining the subsurface structures in the study area, and (5) examining the probable soil contamination due to the wastewater effect.

\section{Location of the study area}

The study area is located some $10 \mathrm{~km}$ west of Erbil city (Fig. 1). It lies between latitudes $36^{\circ} 11^{\prime} 40.60^{\prime \prime} \mathrm{N}$ and longitudes $43^{\circ} 53^{\prime} 05.10^{\prime \prime} \mathrm{E}$, and covers an area of about $7 \mathrm{~km}^{2}$. The dumpsite is on a hill with an elevation
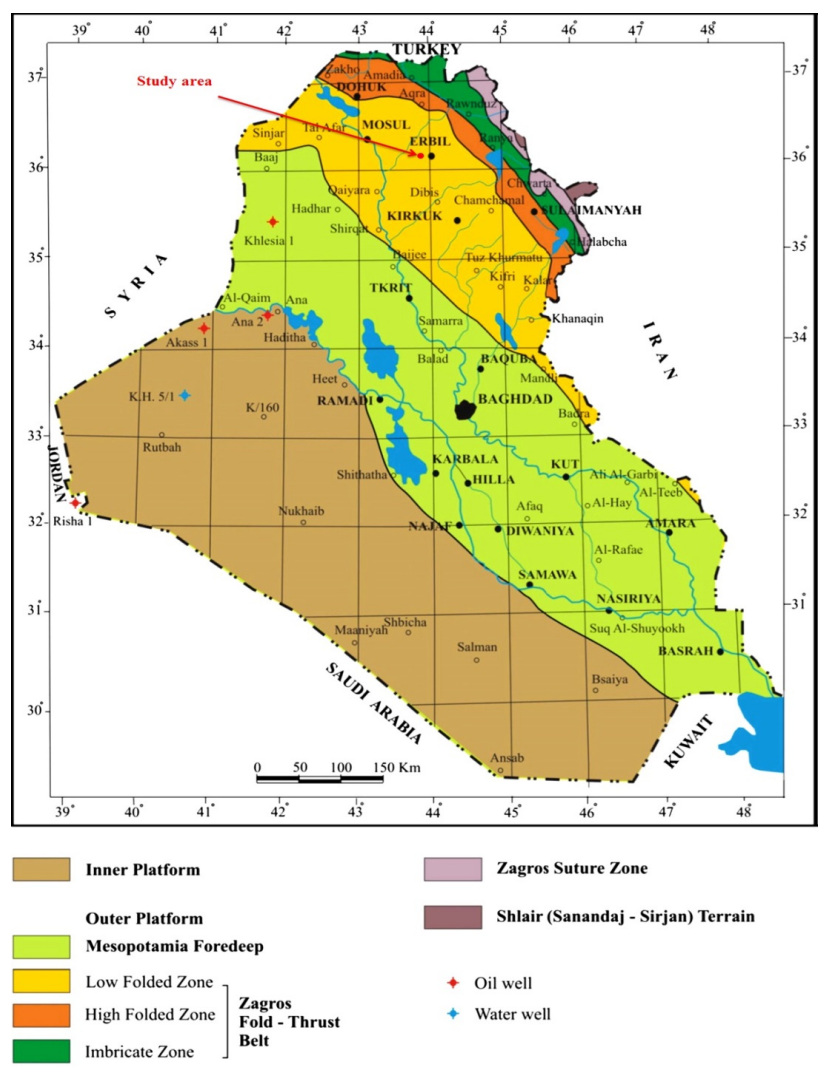

Fig. 1. Main tectonic zones of Iraq (after Fouad, 2010). 
of $\sim 435 \mathrm{~m}$ above sea level. There are two valleys of septic tank discharge besides of the hill which they intersect at the southern part of the hill which they discharge. The prevailing climatic condition in the area of study is characterized by the diurnal variations, high temperature in summer and cold in winter. The climatic condition is important for waste disposal site, because the wind direction and wind speed have a considerable role in generating storms at these sites. The rate of the rainfall is also one of the most important factors, that runoff on the surface of waste disposal sites, seeping as a leachate through it based on the rate of precipitation, finally contact with the groundwater as a contaminant material.

\section{Geological setting}

Geomorphologically there are no surface geological features in the study area, except of some hills and valleys, which are controlled by the drainage pattern, reflecting the subsurface structures and the rock unit nature. The Erbil area rises topographically from the flat plains in the west and southwest towards Pimam Mountain in the north and northeast direction (Fig. 2).

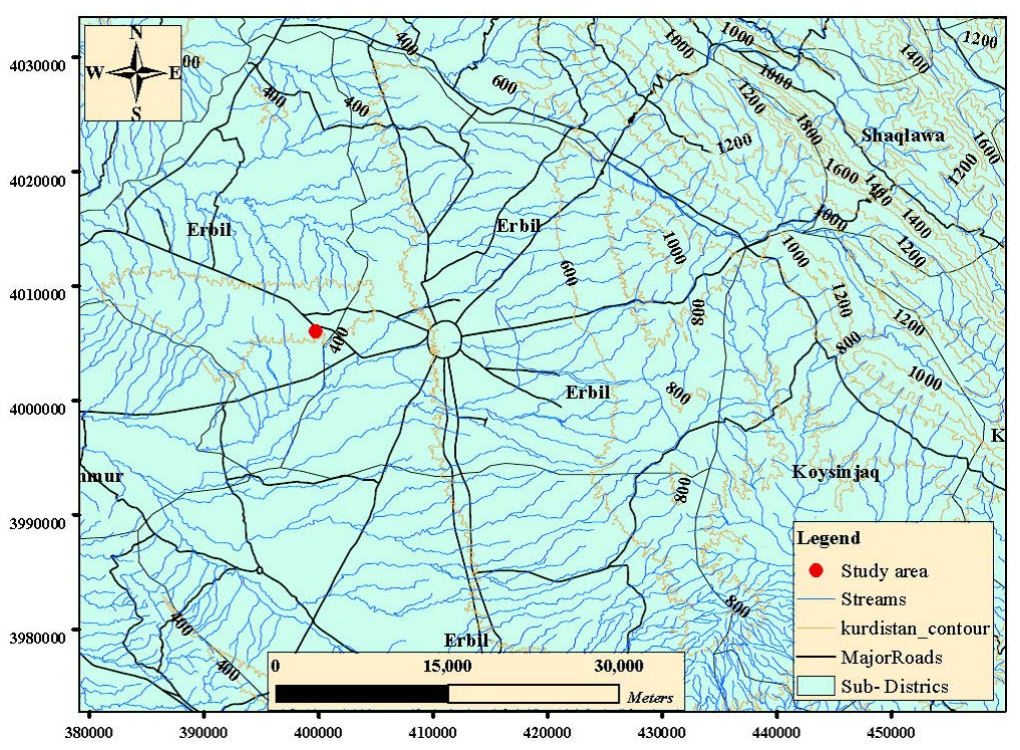

Fig. 2. The study area and topographic map of Erbil province. 
The central plain of Erbil slopes gradually from east to west with a slope of $<3^{\circ}$ where the local slopes do not exceed $8^{\circ}$ (Hassan, 1998). The drainage pattern in Erbil area falls into two subdivisions, the whole of the eastern part of the area that drains from the east, and the northeast with a parallel system of streams and valleys toward the central area just west of Erbil city. This is consistent with the general slope of the area west and southwest from the Pirmam Anticlinal Mountain. The western part of Erbil area on the other hand shows dendritic drainage pattern over gentle slopes of the ground (Ghaib, 2001).

The geological formations exposed in the study area are Mukdadiya (Lower Bakhtiari) and Bai Hassan (Upper Bakhtiari) formations as well as Quarternary and recent sediments. The Mukdadiya Formation (Pliocene) comprises fining upward cycles of gravely sandstone, sandstone, and red mudstone (Jassim and Goff, 2006). The Bai Hassan Formation (Pliocene) which covers most of the study area, consists of molasses sediments represented by alternation of claystones and conglomerates, interbedded with some sandstones and siltstones (Hassan, 1998) (Fig. 3). The Quaternary deposits (Pleistocene-Holocene) consists of mixed gravel and clay forming

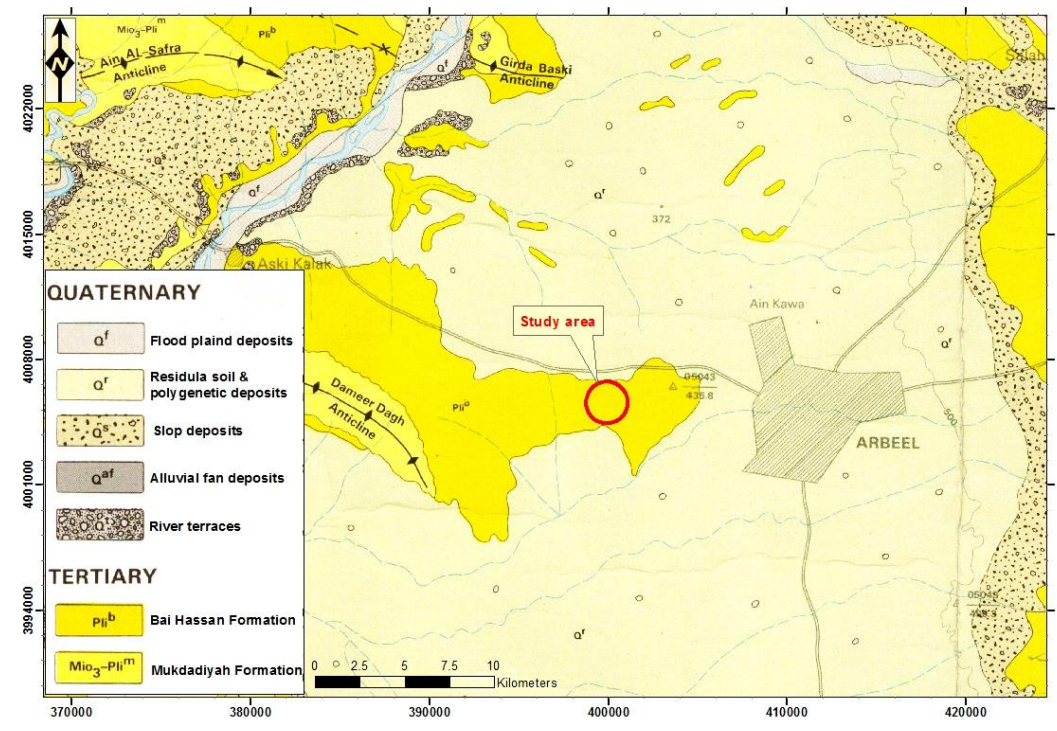

Fig. 3. Geological map showing the study area (after Sissakian, 1997). 
a sedimentary veneer of polygenetic origin covering large areas in the synclines of the foothill zone (Jassim and Goff, 2006).

Structurally, the study area lies within the low folded zone in the stable shelf which is a part of the Arabian Plate, being highly deformed tectonically (Fouad, 2010). The deformation intensity normally decreases from northeast towards southwest indicated rom the decrease in the amplitude of the anticlines, with some exceptions in many parts of the involved area. The anticlinal structures in the northeastern part of Iraq have NW-SE trend, which is parallel to the trend of Zagros Fold-Thrust Zone, and extend northwestwards till the Greater Zab River (Sissakian, 2013) (Fig. 1). The Erbil area is located on the Kirkuk block (Ghaib, 2001). The strata are essentially horizontal with very mild open flexures such as the Erbil trough, and are bounded near the major anticlines by major faults and complicated by many minor faults. The Foothill Zone, especially in the Kirkuk Embayment is characterized by long anticlines with cores of Miocene formations, flanked by very broad and shallow synclines exposing Mio-Pliocene molasse formations along their flanks (Ghaib, 2001). The inner parts of the synclines contain Quaternary deposits, referred to here as the polygenetic synclinal fill (Jassim and Goff, 2006).

Hydrogeologically, the basin of Erbil is bounded from the north by Greater Zab River and from the south by Lesser Zab River. Erbil basin is a wide depression located between southern limb of Pirmam anticline and Dibaga hill zone which gives a semicircular shape to Erbil basin (Majeed and Ahmad, 2002). The Pliocene formations and especially the Bai Hassan, are considered as a major aquifers in the Erbil basin,made up of continental deposit comprising gravel, conglomerate, sand, and clay. The depth of groundwater varies in short distances due to variations in topography. In general, the Erbil Basin is divided into three sub-basins comprising the northern Kapran, the central, and the southern Bashtapa sub-basins (Habib et al., 1990). The study area is located in the central sub-basin which covers an area of $1400 \mathrm{~km}^{2}$. The formations in this sub-basin are the Mukdadiya and Bi Hassan Formations as well as alluvium. According to Hassan (1998), the groundwater table depth ranges between 30 and $50 \mathrm{~m}$ in Erbil City, and according to Al-Ansari et al. (1981), the water table is usually $50 \mathrm{~m}$ deep. According to Hassan (1998), the groundwater flows from east to west side of the Erbil city, the same flow direction of the regional groundwater. 


\section{Results}

\subsection{Geo-electrical resistivity survey}

Schlumberger configuration is used in the field with 4 electrodes, two of them $A$ and $B$ are placed to induce an electric current into ground creating a potential field. The other two additional electrodes are used to measure the potential at the same location (Fig. 4). When two current electrodes $A$ and $B$ are used and the potential difference $(\Delta V)$ is measured between two measuring electrodes $M$ and $N$, the apparent resistivity $\left(\rho_{a}\right)$ can be written in the form:

$\rho_{a}=K \Delta V / I$,

where $K$ is the geometric factor of Schlumberger electrode configuration, expressed by Arshad et al. (2007) as:

$K=\left[\pi\left((A B / 2)^{2}-(M N / 2)^{2}\right) / M N\right]$.

The apparent resistivity $(\rho)$ depends on the geometry of the electrode array used, as defined by the geometric factor $(K)$ (Reynolds, 2011).

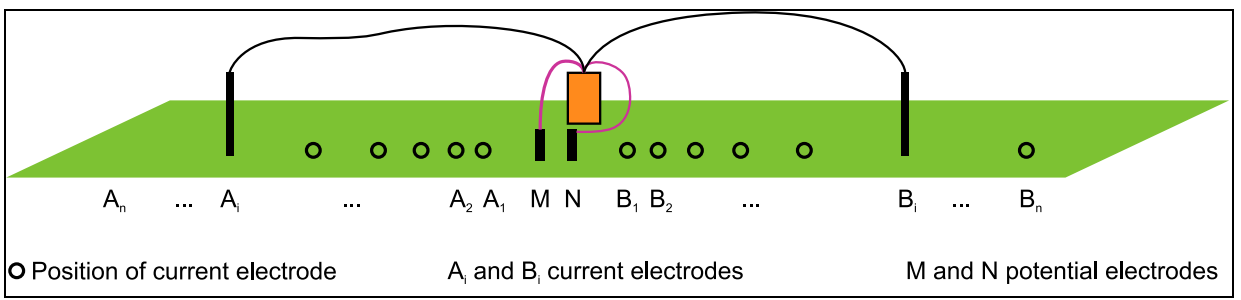

Fig. 4. Sketch of the field setup for a VES in Schlumberger configuration (Kirsch, 2006).

The apparent resistivity is a function of the true layers resistivities, their boundaries, and the location of the electrodes. If the substrata are homogeneous, the apparent resistivity is a good approximation of the true resistivity. The interpreted resistivity in terms of various geological formations is based on a resistivity - depth model that reproduces the observed resistivity from a depth sounding (Asfahani and Radwan, 200\%).

The geoelectrical survey has been adopted in the study area with the purpose of determining the vertical and horizontal distribution of the sedimentary succession, the thickness of the water-bearing layers and detecting 
the subsurface geologic structures to clarify their impact on the groundwater and soil. The geo-electrical resistivity survey has been therefore conducted in the study area by applying the conventional Vertical Electrical Sounding method with 27 VES points. The resistivity meters (Terrameter SAS 300C) used for the field measurements directly measures the resistance $(R)$ with high accuracy for each electrode separation.

The current electrode separation $(A B)$ in the Schlumberger configuration applied in the present investigation (Fig. 4) started from $2 \mathrm{~m}$, and increased successively to reach $600-800 \mathrm{~m}$. Such electrode separations were found to be sufficient to reach a reasonable depth range that modelling the aim of the study. Three of these soundings were conducted beside a drilled well in order to parameterize and calibrate the geo-electrical interpretation.

The orientation of the three survey profiles are (Fig. 5):

Profile $\mathbf{A}-\mathbf{A}^{-}$extends from NW to SE direction for about $700 \mathrm{~m}$ and includes 8 VES points.

Profile $\mathbf{B}-\mathbf{B}^{-}$extends from NW to SE direction for about $800 \mathrm{~m}$ and includes 9 VES points.

Profile $\mathbf{C}-\mathbf{C}^{-}$extends from NE to SW direction for about $900 \mathrm{~m}$ and includes 10 VES points.

The sounding spacing was about $100 \mathrm{~m}$; the spreading of electrodes is parallel to the general NW-SE structure direction around the study area, to avoid the influence of dip on the resistivity measurements (Al-Ane, 1983).

\subsection{Data processing}

The geo-electrical sounding curves carried out in the study area have been accurately interpreted using an inverse technique program (Bobachev et al., 2001) applied for the 1D qualitative and quantitative interpretation. Fig. 6 shows different examples of field curves along traverses $\mathrm{A}-\mathrm{A}^{-}, \mathrm{B}-\mathrm{B}^{-}$ and $\mathrm{C}-\mathrm{C}^{-}$interpreted by using this IPI2win (2001) program (Bobachev et $a l$. , 2001). It is interactive software, graphically oriented, forward and inverses modelling program for interpreting the resistivity curves in terms of a layered earth model. 


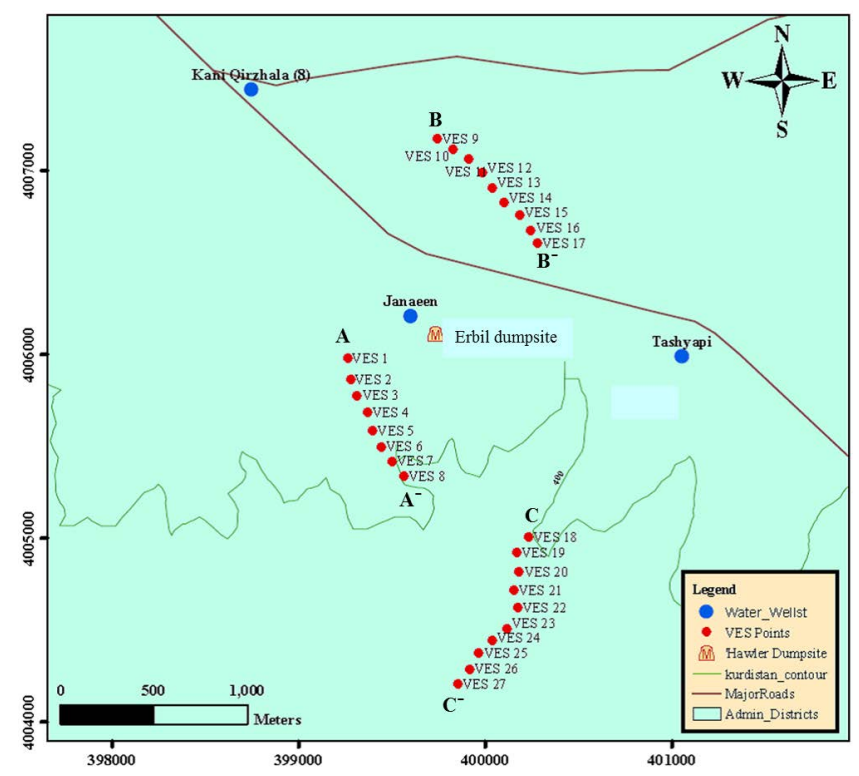

Fig. 5. Map showing the VES points and calibration wells at the study area.

\subsection{The Pichgin and Habibullaev technique}

This technique is one of the most developed methods used to detect tectonically fractured zones and faults with the determination of their direction and dip amounts through different types of rocks; hence a subsurface 2D tectonic image can be obtained. It can be easily applied to a series of VES points distributed along a given profile. The principle of this technique (Fig. 7) can be summarized as follows: When an electrical current penetrates a planar contact between two different rocks having different resistivities like: $\rho_{1}$ and $\rho_{2}$, then the electrical field boundary conditions at this contact are characterized as below (Asfahani, 2011):

1. If the center point of the vertical electrical sounding is exactly located over a vertical contact between two different formations of different resistivities $\left(\rho_{1}\right.$ and $\rho_{2}$ ), and the electrode array is perpendicular to this contact (Fig. 8a), then the resulting measured resistivity $\rho_{K}$ is given by the following equation:

$\rho_{K}=\left(\rho_{1}+\rho_{2}\right) / 2$. 
2. If the array is parallel to such a contact, then the resulting measured resistivity $\rho^{\prime} K$ is given by the following equation: $\rho^{\prime} K=2\left(\rho_{1} \rho_{2}\right) /\left(\rho_{1}+\rho_{2}\right)$.

In both of these cases, resistivity is independent of the distances between the two current electrodes, or between the two potential electrodes.

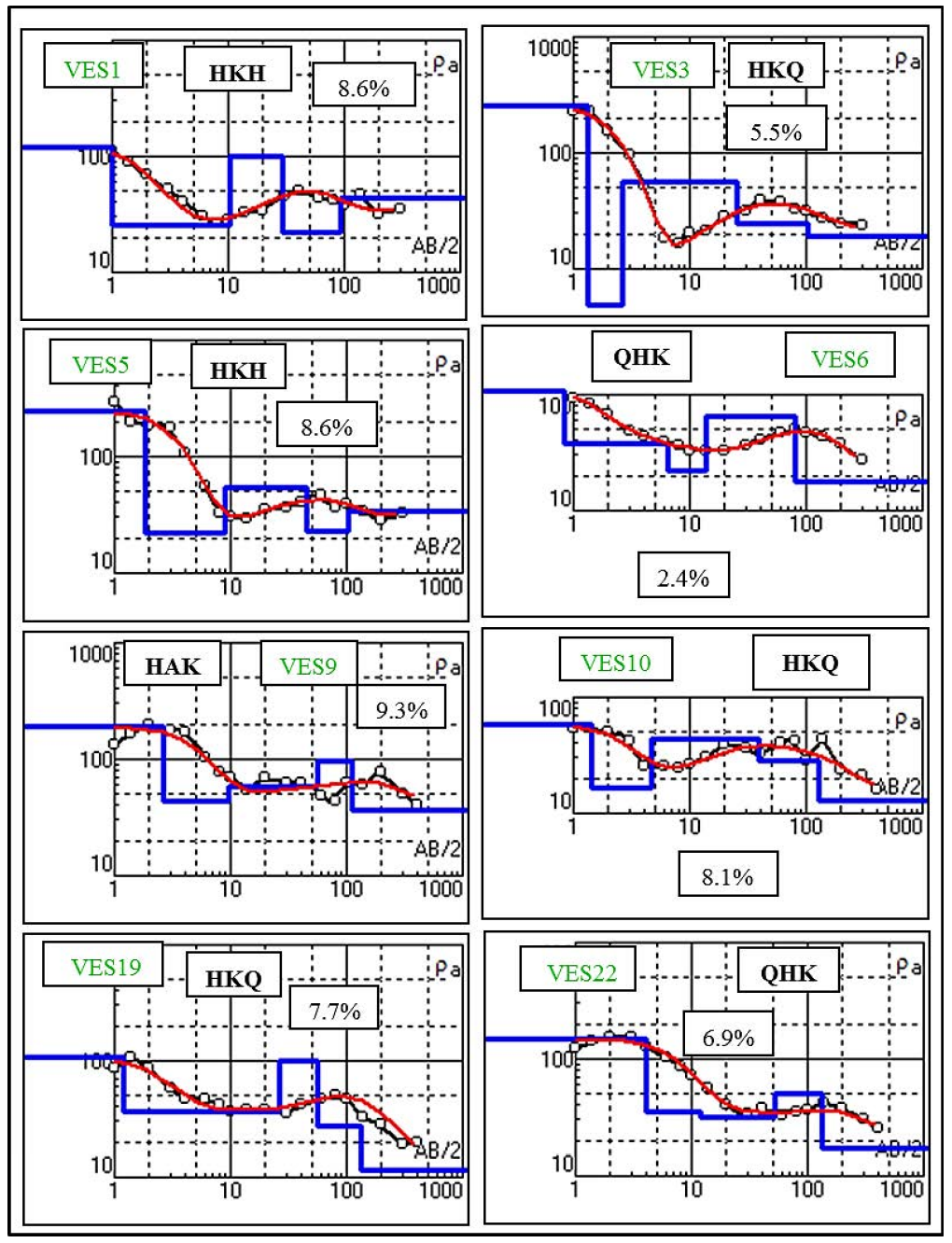

Fig. 6. Examples of field curves along traverses $\mathrm{A}-\mathrm{A}^{-}, \mathrm{B}-\mathrm{B}^{-}$and $\mathrm{C}-\mathrm{C}^{-}$interpreted by IPI2win (2001) program. VES1: VES point, HKQ: curve type and $8 \%$ error percentage. 
If two vertical electrical soundings, VES1 and VES2, are performed on either side of a vertical contact, then all profile curves for every given current electrode half-spacing $(A B / 2)$ will intersect at a point located directly over this vertical contact. The locations of the vertical electrical soundings carried out on a given profile are plotted on the abscissa, and corresponding apparent resistivities $\left(\rho_{K}\right.$ or $\left.\rho_{K}^{\prime}\right)$ for each given $A B / 2$ are plotted on the ordinate, as shown in Fig. 8.

The intersection points of the curves, that are termed "points of nonhomogeneity" (PNH), are plotted on a 2D $(x, y)$ geological section (Fig. 8c).

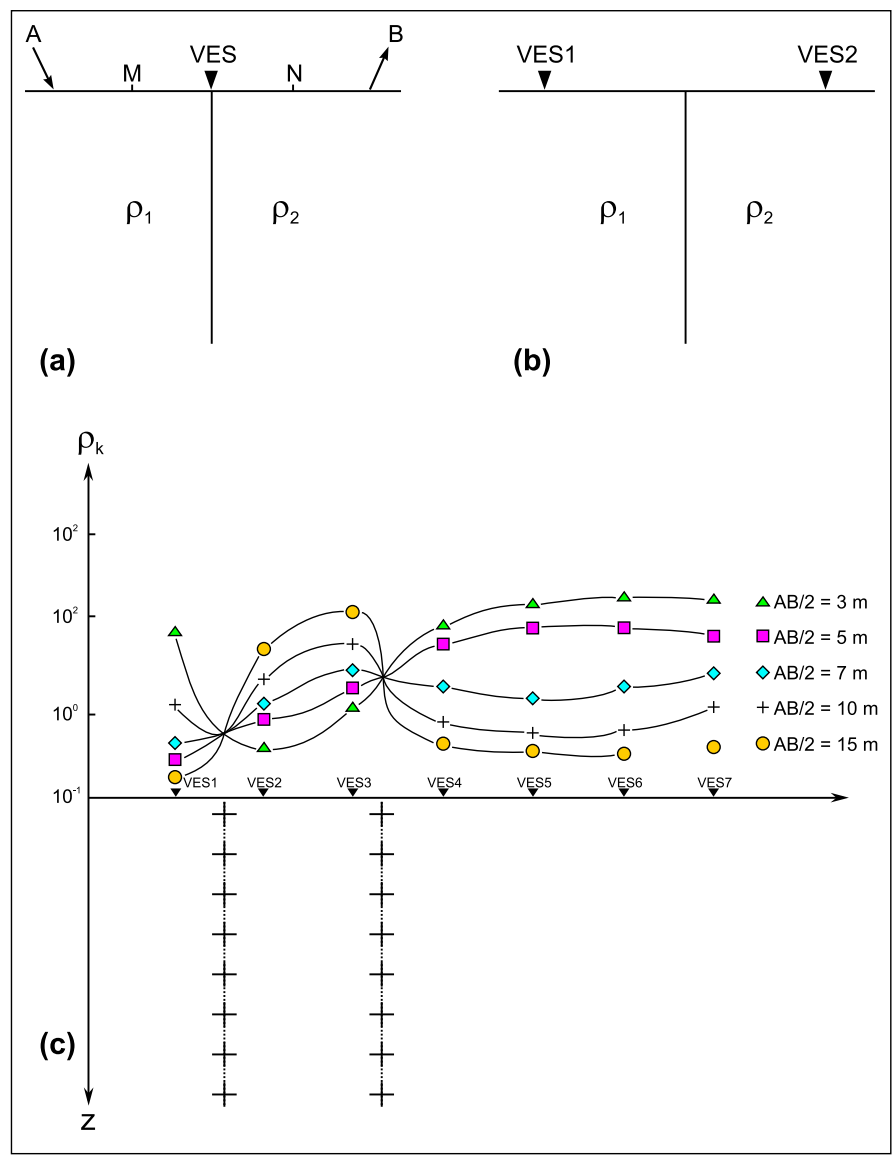

Fig. 7. Principle of Pichgin and Habibullaev method (after Asfahani, 2011). 
The depth $(Z)$ of each PNH can be determined from to the following equation:

$Z=\left[(A B / 2)_{i}+(A B / 2)_{j}\right] / 2$,

where $(A B / 2)_{i}$ and $(A B / 2)_{j}$ are the half-spacings between the electrodes $A$ and $B$, at which two horizontal curves intersect. The locations of the PNH can be determined using a computer program developed by Asfahani and Radwan (2007). The fractured zones are determined according to the distribution of PNH along the studied profile.

According to the Pichgin-Habibullaev technique, geological interpretation of the PNH is based on the following assumptions:

1. When the PNH are distributed as oblique lines located at shallow depths, they indicate the presence of an inhomogeneous lithological contact.

2. If they are arranged along oblique lines dipping at an angle exceeding $30^{\circ}$ at depth, then they represent a fractured zone.

3. If they are scattered randomly near the surface, then they indicate a homogeneous lithology.

4. If they are arranged in regular forms, then they might reflect certain geological structures, such as synclines, anticlines, or horizontally layered strata.

These assumptions have been verified and calibrated through several field tests in Syria involving different lithology and structural architecture (e.g.: Asfahani and Mohamad, 2002; Asfahani and Radwan, 2007; Asfahani et al., 2010; Al-Fares and Asfahani, 2018). In particular, Asfahani and Radwan (2007) improved this technique to acquire accurate subsurface structural information by taking into consideration the real topographic variations along the studied VES profile.

\section{Interpretation of the measured data}

The measured data of each VES points have been interpreted qualitatively and quantitatively to delineate the subsurface materials in the study area. 


\subsection{Quantitative 1D interpretation}

The ID quantitative interpretation of the 27 VES curves provided both the true model resistivities and thicknesses of each VES (Gardi, 2017). This interpretation has been processed with the use of available calibrated geologic information. The obtained interpretative results are plotted using IPI2win software as shown in figure 6 . At the end of data processing and interpretation, the layer parameters (true resistivities and thicknesses or depths) of the various current penetrated layers can be obtained (El-Sayed, 2010). The general geologic setting and relevant information have been obtained from three of the generated geo-electrical profiles crossing the study area in different directions (Table 1).

Table 1. The geometry and electrical characteristics of Bai Hassan Formation in the study area.

\begin{tabular}{|c|c|c|l|}
\hline $\begin{array}{l}\text { Layer } \\
\text { No. }\end{array}$ & $\begin{array}{l}\text { Ranges of true } \\
\text { resistivity }(\Omega \mathrm{m})\end{array}$ & $\begin{array}{l}\text { Ranges of } \\
\text { thickness }(\mathrm{m})\end{array}$ & Lithology \\
\hline 1 & $28-421$ & $0.25-6.19$ & $\begin{array}{l}\text { A thin layer of medium to coarse grained } \\
\text { sand and gravel (Top soil) }\end{array}$ \\
\hline 2 & $20.3-50.0$ & $22.0-49.0$ & Sand and silt \\
\hline 3 & $35.8-99.2$ & $8.0-69$ & Gravel and sand \\
\hline 4 & $11.0-50.0$ & $1.0-33.0$ & Sand silt and clay \\
\hline 5 & $37.0-322$ & $6.0-96.0$ & Mixture of gravel, sand, silt and clay \\
\hline 6 & $11.0-50.0$ & $40.0-101.0$ & $\begin{array}{l}\text { Sand, silt and clay saturated with ground- } \\
\text { water }\end{array}$ \\
\hline 7 & $10.20-43.7$ & - & Silt and clay saturated with groundwater \\
\hline
\end{tabular}

\subsection{Quantitative 2D interpretation by Pichgin and Habibullaev (1985) technique}

Pichgin and Habibullaev (1985) technique is used to get the final subsurface model of each studied profile, where the results of 1D VES interpretations of the VES points distributed along the studied profile are superimposed. The geoelectrical section will show the vertical and lateral distribution of resistivities of subsurface layers. Each layer in the geoelectrical section profile is characterized by its thickness and ranges of true resistivity, that will give an idea of the kind of rock present in the subsurface, and hence, a 
model of the subsurface can be prepared (Oghenekohwo, 2008).

The resulting geoelectric models are used to produce three geological cross sections: $\mathrm{A}-\mathrm{A}^{-}, \mathrm{B}-\mathrm{B}^{-}$, and $\mathrm{C}-\mathrm{C}^{-}$. Each section has its characteristics of true resistivity and depth, its lithology and in structural view, can be interpreted in detail. The generated geo-electric sections reveal that the area is generally characterized by five geo-electric layers.

\subsubsection{Pichgin and Habibullaev Profile $\mathrm{A}-\mathrm{A}^{-}$(Fig. 8)}

The distribution of points of non-homogeneity (PNH) derived by the Pichgin and Habibullaev technique provides information about the subsurface structures and bedded units along the study profile. Three clear faults have been identified in this profile (Fig. 8a); the first one is nearly vertical deep fault which is located almost under VES3 from depth $50 \mathrm{~m}$ to $230 \mathrm{~m}$. Another two faults with reverse direction to each other starts from nearly $40 \mathrm{~m}$ to $90 \mathrm{~m}$. The non-homogeneity area has been detected which may reflect the burial paleochannel in this section, that is very dominant in the Bai Hassan Formation with a distance of $\sim 200 \mathrm{~m}$ and a depth of $60 \mathrm{~m}$ which starts from the beginning of the section until VES3.

The pseudo-section showed that at the nearly surface the VES2 and VES7 of this profile are characterized by low apparent electrical resistivity values indicating that this area is affected by the septic tank water. The highly resistive strata under VES3 and VES6 have been noticed (Fig. 8b). There seem to exist a significant fracturing around VES3 and VES6, as these portions have high resistive materials compared to other VES points.

\subsubsection{Pichgin and Habibullaev Profile $\mathrm{B}^{-} \mathrm{B}^{-}$(Fig. 9)}

Nine faults have been detected in the structural view of this section which was interpreted by Pichgin and Habibullaev method. Five of them are deep faults ranging in depth between $20 \mathrm{~m}$ to $300 \mathrm{~m}$ (Fig. 9a). Seven of these faults start at depth of $\sim 20 \mathrm{~m}$ with different lengths and the same direction; the one nearly located under VES9 starts at depth about $180 \mathrm{~m}$ to $300 \mathrm{~m}$; while the other one located around VES11 starts from $80 \mathrm{~m}$ to $180 \mathrm{~m}$ depth. Generally three convex areas have appeared in the beginning, middle and 


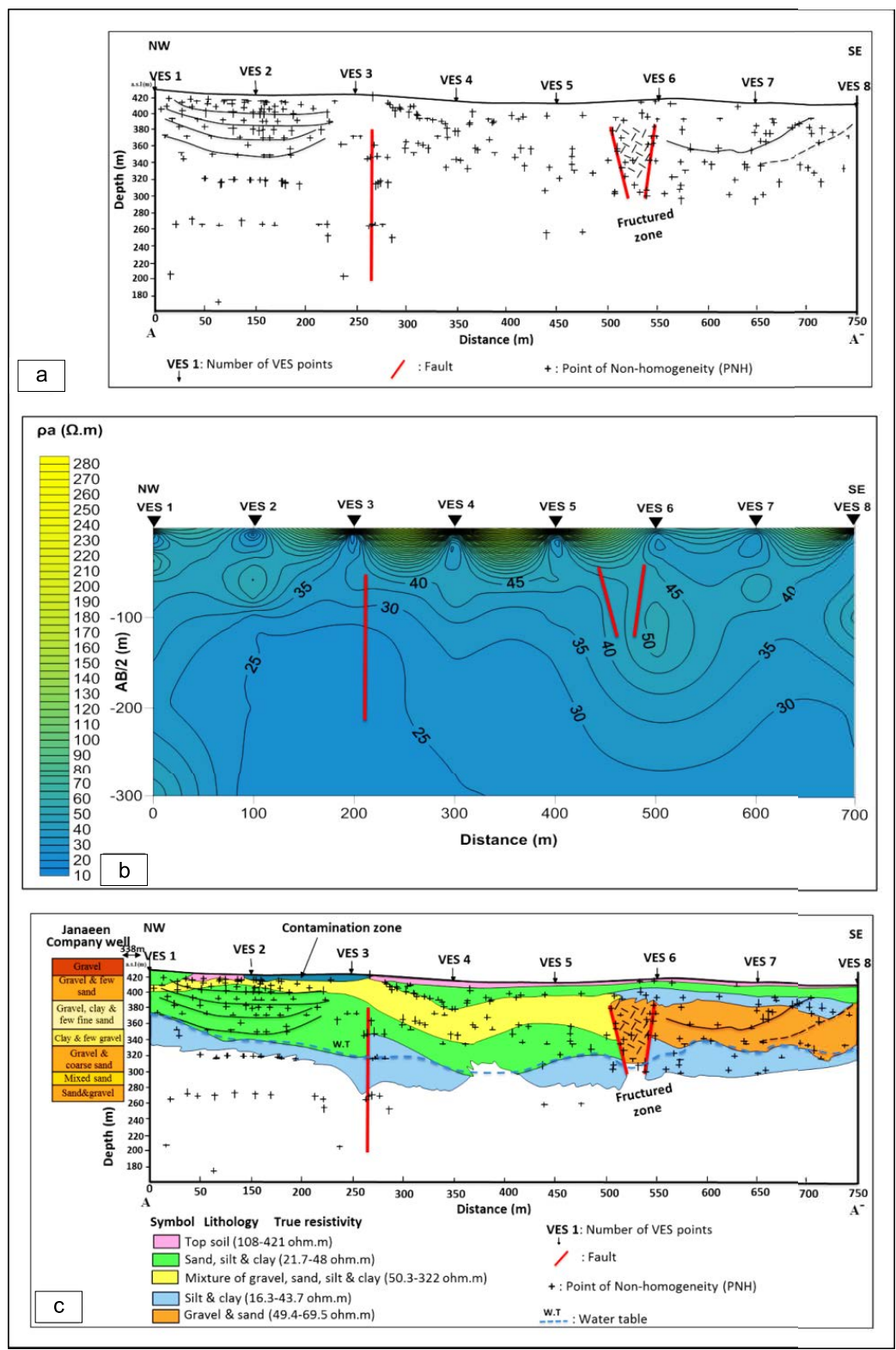

Fig. 8. Three sections along profile $\mathrm{A}-\mathrm{A}^{-}$. (a) Pichgin and Habbullaev non homogeneity points section, (b) pseudo-section, and (c) final geo-electrical section. 


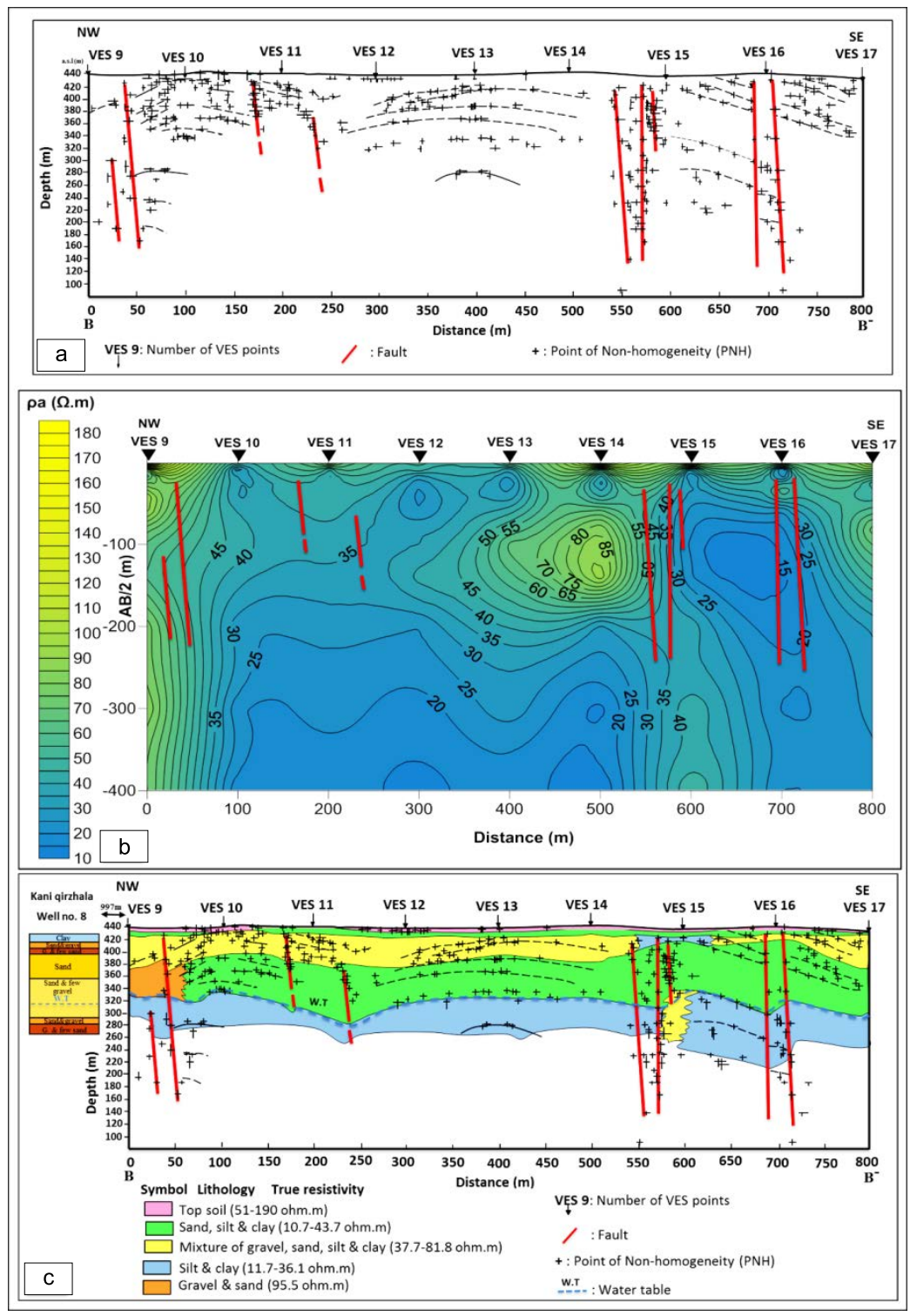

Fig. 9. Three sections along profile $\mathrm{B}^{-\mathrm{B}^{-}}$. (a) Pichgin and Habbullaev non homogeneity points section, (b) pseudo-section, and (c) final geo-electrical section. 
the last part of the section which have been detected by points of nonhomogeneity. These areas mean they are affected during faulting activity and getting bended, which may causes small fractures of the layers.

The pseudo-section has VES points 9, 14, 15 and 17 revealing a uniform increase in resistivity with depth and a comparative medium resistivity throughout the profile too. A slightly closed packing of contour occurs around VES14 and VES7 between $50 \mathrm{~m}$ and $150 \mathrm{~m}$ depth (Fig. 9b), likely indicating deep fracturing.

\subsubsection{Pichgin and Habibullaev Profile $\mathrm{C}-\mathrm{C}^{-}$(Fig. 10)}

In this profile two different anomalies have been detected at the shallow depth. The first anomaly under VES19 and the second anomaly lie directly under the VES25; they represent the burial paleochannel, which is detected by the points of non-homogeneity with different shapes due to their different lithology. This profile has been affected by the presence of six faults, three of them are located at the left of the section with depth ranging from $130 \mathrm{~m}$ to 300,340 and $380 \mathrm{~m}$ respectively, and the other faults are located at the right of the section, which two of them start from $130 \mathrm{~m}$ representing and the last one is about $200 \mathrm{~m}$ to $360 \mathrm{~m}$ (Fig. 10a). The direction of these two set of faults are different otherwise one of them changes its direction with penetrating the depth, under VES20. In the center of this section, the effect of the tectonic activity has been detected (bended), its trace is very clear and not has cut but the faults yet or may affected by the force of the opposite sets of faults.

The pseudo-section showed that faults are also inferred in this profile around VES19, 20 and 26 at depth (Fig. 10b). However, the presence of competent formation at the top to the subsurface and an obvious lack of fracturing may impede percolation of groundwater.

\subsubsection{Geological cross sections}

Five to seven different geological lithologies have been detected through quantitative interpretation of measured resistivities along three profiles (Table 1). 


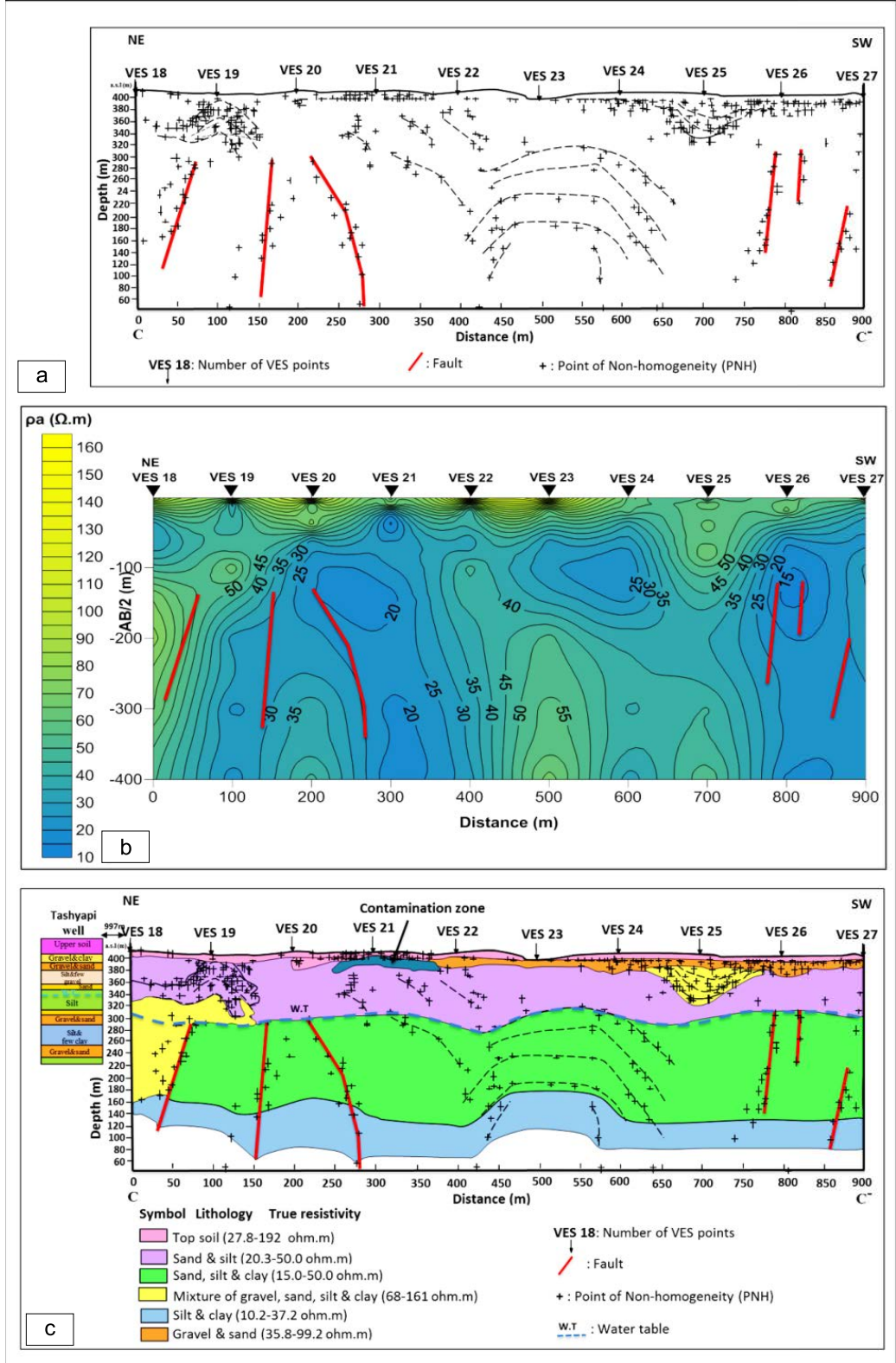

Fig. 10. Three sections along profile $\mathrm{C}^{-} \mathrm{C}^{-}$. (a) Pichgin and Habbullaev non homogeneity points section, (b) pseudo-section, and (c) final geo-electrical section. 
The first layer is a continuous thin surface nearly horizontal geo-electric layer representing the top soil with resistivity ranges of $47-421 \Omega \mathrm{m}, 51-$ $191 \Omega \mathrm{m}$, and $28-192 \Omega \mathrm{m}$ for $\mathrm{A}-\mathrm{A}^{-}, \mathrm{B}-\mathrm{B}^{-}$, and $\mathrm{C}^{-} \mathrm{C}^{-}$profiles, respectively. These variations in resistivity value occur due to various types of sediments, fine and medium to coarse grained sand and gravel with variable sizes. The thickness varies from $0.25-1.85 \mathrm{~m}, 0.5-2.5 \mathrm{~m}$ and $0.8-6.0 \mathrm{~m}$ (Figs. 8c, 9c, and 10c).

This layer is located in a contaminated area and shows a low resistivity ranging from 3.0-4.0 $\Omega \mathrm{m}$ under VES2 and VES3 compared to those of the uncontaminated layer outside the disposal site and thickness of 1.0-1.5 m. It is probably contaminated with the septic tanks discharge.

The second geo-electrical layer has resistivity range of $20.3-50.0 \Omega \mathrm{m}$ and thickness range of 22.0-49.0 m. It is composed of sand and silt, which was found only in the third profile. A small scale slump folding is identified within this layer under VES19 directly which is detected by the Pichgen and Habibullaev interpretation by NHP representing a style of soft sediment deformation. When sediment on a slope is liquefied, it tends to flow or slide downs the slope even if the slope angle is only few degrees. Various patterns of folding develop; with down slope vergence of the folds takes place, up to few meters in scale. Sometimes these folds are truncated by erosion and overlain by very similar sedimentary material, emphasizing the slight depth of burial of material when it is deformed (Van Loon, 2009). The intensity of folding in these narrow zones within otherwise undeformed sequences and the minimum of shearing and fracturing indicate the extreme plasticity, verging on fluidity, of the sediments during deformation (Gregory, 1969). A buried paleochannel has been detected within this layer under VES25, which is composed of a mixture of gravel, sand, silt and clay with resistivity range of $67.0-161.0 \Omega \mathrm{m}$ and thickness range of $25.0-36.0 \mathrm{~m}$ (Fig. 11c).

The third layer has resistivity range of $49.4-69.5 \Omega \mathrm{m}$ that represent massive body of highly fractured sand and gravel with thickness range of 50.0$66.0 \mathrm{~m}$ toward southeast direction of the study area and was affected by two faults in the reverse direction with each other, from nearly $40-90 \mathrm{~m}$ in the first profile (Fig. 8c). The same layer is observed in the second profile under VES9 and has high resistivity value of $95.5 \Omega \mathrm{m}$ with $\sim 69.0 \mathrm{~m}$ thickness (Fig. 9c). In the third profile, this third layer is detected as the second 
geo-electrical layer having resistivity range of $35.8-99.2 \Omega \mathrm{m}$ and thickness range of 8.0-33.0 $\mathrm{m}$ from VES22-VES27 (Fig. 10c).

The fourth geo-electrical layer consists of slightly fine grained sediments which have lower resistivity value than the first one ranging from 21.7$48.0 \Omega \mathrm{m}$ and $10.7-43.7 \Omega \mathrm{m}$ for the $\mathrm{A}-\mathrm{A}^{-}$and $\mathrm{B}-\mathrm{B}^{-}$profiles, respectively. The thickness of this layer ranges from $1.0-18.0 \mathrm{~m}$ and $3.0-13.0 \mathrm{~m}$. This thin layer is not identified in the $\mathrm{C}^{-} \mathrm{C}^{-}$profile. The resistivity is diagnostic of fine grained sediments such as sand, silt and clay. In the $\mathrm{C}^{-} \mathrm{C}^{-}$profile a lens with low resistivity value of $\sim 2.0 \Omega \mathrm{m}$ with a thickness of $\sim 4.5 \mathrm{~m}$ beneath VES21 has been detected (Fig. 10c). This lens may represents the contaminated area because it is susceptible to contamination by septic tank discharges.

The resistivity of the fifth geo-electrical layer in the $\mathrm{A}-\mathrm{A}^{-}$profile range from $50.0-322.0 \Omega \mathrm{m}$ with a thickness range of $6.0-41.0 \mathrm{~m}$. This layer is composed of a mixture of gravel, sand, silt and clay. The resistivity value under VES2 is too high $\sim 322 \Omega \mathrm{m}$ (Fig. 8c), due to increase of the ratio of gravel toward the northwest compared to the other continuous VES points. The resistivity of this geo-electric layer in the $\mathrm{B}^{-} \mathrm{B}^{-}$profile ranges from $37.0-$ $81.8 \Omega \mathrm{m}$ and a thickness range of $20.0-58.0 \mathrm{~m}$ which thins to $\sim 20.0-23.0 \mathrm{~m}$ under VES16. This layer is composed of a mixture of gravel, sand, silt and clay, and highly fractured due to faulting. It contains a lens of silt and clay of $20.4 \Omega$ m resistivity and $\sim 23 \mathrm{~m}$ thickness under VES point 15 . Five faults have been noticed within this layer which was also explained in the Pichgen and Habibullaev section (Fig. 10a and c). This geo-electrical layer in the $\mathrm{C}-\mathrm{C}^{-}$profile has a resistivity range of $68.0-161.0 \Omega \mathrm{m}$ and a thickness range of $55.0-96.0 \mathrm{~m}$.

The sixth geo-electrical layer of the $\mathrm{A}-\mathrm{A}^{-}$profile has a resistivity range of $21.0-26.0 \Omega \mathrm{m}$ and a thickness range of $40.0-76.0 \mathrm{~m}$. This layer consists of sand, silt and clay. The non-homogeneity area has been detected, which may reflect the buried paleochannel within this layer which is very dominant in the Bai Hassan Formation. This paleochannel starts from the beginning of the section until VES3. A fault was detected almost under VES3 from depth $50 \mathrm{~m}$ to $230 \mathrm{~m}$. This layer changes laterally in the southeast direction to sand and gravel with sand, silt and clay due to compression process which initiates faulting (Fig. 8c). This layer has been shown also in the beginning of the $\mathrm{B}^{-} \mathrm{B}^{-}$profile (Fig. 9c) with a resistivity range of $11.0-32.0 \Omega \mathrm{m}$ and a 
thickness of 54.5-101.0 m. It consists of sand, silt and clay which is characterized by highly fractured medium as reflected by non-homogeneity points at the beginning and the middle of the section. While the VES9 has high resistivity value of $95.5 \Omega \mathrm{m}$ with $\sim 69.0 \mathrm{~m}$ thickness, may be interpreted as gravel and sand layer. Generally, the tectonic activity that affected this layer is due to its soft sediments. This layer of the $\mathrm{C}^{-} \mathrm{C}^{-}$profile is observed with relatively higher resistivity than other geo-electrical sections, ranging from $15-50 \Omega \mathrm{m}$, except under VES point 18 which has $69.0 \Omega \mathrm{m}$ resistivity due to change of lithology to a mixture of gravel, sand, silt and clay. This horizon consists of sand, silt and clay which constitute an aquifer of good quality groundwater. The thickness of this aquifer ranges from $55.0-96.0 \mathrm{~m}$ depth. This layer has been affected by six faults, three of them are located at the left of the section with depth range of $130 \mathrm{~m}$ to 300,340 and $380 \mathrm{~m}$, respectively; the other three faults are located at the right of the section where two of them start from $130 \mathrm{~m}$ and the last one from $\sim 200 \mathrm{~m}$ to $360 \mathrm{~m}$. In the center of this section, the effect of the tectonic activity has been detected (bended), but its trace is very clear and not has cut by the faults yet.

The seventh geo-electrical layer which constitutes an aquifer of groundwater in both profiles $\mathrm{A}-\mathrm{A}^{-}$and $\mathrm{B}-\mathrm{B}^{-}$has resistivity value ranging from 16.0-43.7 $\Omega \mathrm{m}, 11.7-36.1 \Omega \mathrm{m}$, and 10.2-37.2 $\Omega \mathrm{m}$, respectively (Figs $8 \mathrm{c}$ and 9c). The thickness of this layer is not defined since it is the last layer. This layer shows lateral lithological variations to coarser material with a resistivity of $61.0 \Omega \mathrm{m}$ under VES points 15 representing a mixture of gravel, sand, silt and clay. This layer is also affected by tectonic activity and seven faults have been observed (Fig. 9c).

\section{Discussion}

The interpretation results of the three geo-electrical sections in the study area indicate the presence of a basin and show successions with variable lithology and thickness. These lithologies reflect the Bai Hassan Formation based on Buday (1980) who defined the formation as sediments represented by alternation of clays and conglomerate with some sandstones and siltstones. The successive layers of this formation represent the coarsening upward due to progression processes where many soft structural deformations 
were detected and a lot of subsurface structures like faults with different directions and dimensions due to tectonic activity in the study area.

Generally, each studied profile is composed of five layers, the first layer for all those profiles represent the top soil. The second layer represents sand, silt and clay in both first two profiles. Where mixed gravel, sand, silt and clay layer divides this layer. This mixed layer changes to another two layers like silt and clay with a massive body of gravel and sand and very clear two reverse faults in the first profile (Fig. 8c). This layer of gravel and sand was observed in the beginning of the $\mathrm{B}^{-} \mathrm{B}^{-}$profile too (Fig. 9c); while it has shown as a thin layer in the $\mathrm{C}^{-} \mathrm{C}^{-}$profile (Fig. 10c). The gravel and sand layer represent the large paleochannel in such a model. The main layer of sand, silt and clay represents an aquifer in the $\mathrm{C}^{-} \mathrm{C}^{-}$profile which was highly fractured by six faults detected by $\mathrm{PNH}$ of Pichgen and Habibullaev (1985) method (Fig. 10c).

The last layer composed of silt and clay is representing an aquifer in the study area in both $\mathrm{A}-\mathrm{A}^{-}$and $\mathrm{B}-\mathrm{B}^{-}$profiles (Figs. $8 \mathrm{c}$ and $9 \mathrm{c}$ ). According to Stevanovic and Iurkiewicz (2009), it consists almost entirely of terrigenous clastics made up of silt size to boulder conglomerates eroded and transported from the Zagros Mountains. The successive repetition of the fine-, medium- and coarse- grained textures, and the variation in permeability from one site to another within the same aquifer layer, are typical characteristics of this aquifer. The groundwater level has been detected by the value of resistivity layers and borehole information too, in addition to the Pichgen and Habibullaev (1985) method. This gives a clear clue for detecting groundwater level by the absence or discontinuous PNH through the groundwater level (Figs. 8c, 9c and 10c). This technique is very helpful to confirm and detect groundwater level without doubt.

The depth to the top of the aquifer from the surface is approximately ranging from $35.0-129.0 \mathrm{~m}$ (Table 2). The deep water table has been detected ranging from 55.0-94.0 m in parts of Erbil city by Ghaib and Aziz, (2002). There is a conducted deeper water table that may be due to the drought condition, which is facing our region since that time.

In this paper, researchers purposely select the mentioned $A B / 2$ spacing that are capable to show the effect of contamination, which is related to the environment. We found from the results of geo-electrical resistivity that the contaminated area is characterized by its low resistivity value com- 
Gardi S. Q. S., Asfahani J.: Subsurface tectonic characterizations...

Table 2. Depth, resistivity and elevation of the top surface of aquifer.

\begin{tabular}{|c|c|c|c|c|}
\hline VES No. & $\begin{array}{l}\text { Elevation } \\
\text { a.s.l. }(\mathrm{m})\end{array}$ & $\begin{array}{l}\text { Depth to the top } \\
\text { of aquifer }(\mathrm{m})\end{array}$ & $\begin{array}{l}\text { Elevation of top surface } \\
\text { of aquifer a.s.l. }(\mathrm{m})\end{array}$ & $\begin{array}{l}\text { Resistivity of } \\
\text { aquifer }(\Omega \mathrm{m})\end{array}$ \\
\hline VES1 & 426 & 94.7 & 421.3 & 43.7 \\
\hline VES2 & 420 & 75.1 & 344.9 & 17.6 \\
\hline VES3 & 423 & 102.0 & 321.0 & 18.8 \\
\hline VES4 & 413 & 102.0 & 311.0 & 17.7 \\
\hline VES5 & 411 & 102.0 & 309.0 & 33.6 \\
\hline VES6 & 414 & 80.1 & 333.9 & 17.8 \\
\hline VES7 & 407 & 83.0 & 324.0 & 22.2 \\
\hline VES8 & 407 & 83.1 & 323.9 & 16.3 \\
\hline VES9 & 438 & 111.0 & 327.0 & 36.1 \\
\hline VES10 & 440 & 127.0 & 313.0 & 12.8 \\
\hline VES11 & 438 & 127.6 & 310.4 & 14.9 \\
\hline VES12 & 434 & 127.0 & 307.0 & 11.7 \\
\hline VES13 & 434 & 128.0 & 306.0 & 12.9 \\
\hline VES14 & 437 & 116.0 & 321.0 & 10.2 \\
\hline VES15 & 429 & 131.0 & 298.0 & 61.0 \\
\hline VES16 & 432 & 126.0 & 306.0 & 26.7 \\
\hline VES17 & 423 & 129.0 & 294.0 & 21.0 \\
\hline VES18 & 414 & 76.2 & 337.8 & 69.0 \\
\hline VES19 & 400 & 56.5 & 343.5 & 26.9 \\
\hline VES20 & 402 & 53.1 & 348.9 & 22.2 \\
\hline VES21 & 403 & 42.7 & 360.3 & 29.5 \\
\hline VES22 & 398 & 52.6 & 345.4 & 49.9 \\
\hline VES23 & 392 & 58.7 & 333.3 & 28.2 \\
\hline VES24 & 393 & 43.3 & 349.7 & 25.2 \\
\hline VES25 & 391 & 35.6 & 355.4 & 30.0 \\
\hline VES26 & 385 & 41.1 & 343.9 & 15.1 \\
\hline VES27 & 388 & 36.9 & 351.1 & 33.6 \\
\hline
\end{tabular}

pared with the surrounding area. The contamination zone is detected in the geo-electrical sections along $\mathrm{A}-\mathrm{A}^{-}$profile under VES points 2 and 3 and $\mathrm{C}-\mathrm{C}^{-}$profile under VES21 in the contaminated area by septic tanks. It can flow by infiltration from the surface downward due to the high porosity and permeability of the lithology. If this process is continued, it may come to 
contact with groundwater surface and finally contaminate the groundwater. The depth that is subject to contamination from the surface is $\sim 1.0-18.0 \mathrm{~m}$. The contamination zone has not been detected by the geo-electrical section along profile $\mathrm{B}-\mathrm{B}^{-}$because it is far away from the dumpsite and septic tank impacts.

Generally, the study area is affected by a number of faults and fractured rock bodies due to the tectonic activity that have been detected by applying Pichgin and Habibuleave technique. 18 faults have been detected, where three faults of them are in the first profile $\left(A-A^{-}\right)$, nine faults are in the second profile $\left(\mathrm{B}-\mathrm{B}^{-}\right)$, and the other six faults are in the last profile $\left(\mathrm{C}^{-} \mathrm{C}^{-}\right)$. As it has been seen, the second and third profiles have been more affected than the first one. Most of these faults occur within the fourth layer of the geo-electrical sections that is composed of sand, silt and clay layer saturated with water (aquifer), and extends from the depth of $\sim 50.0-360.0 \mathrm{~m}$. In addition to those areas of non-homogeneity, points were detected in all profiles which may represent the fractured body within the same layer and two clear buried paleochannel in first and third sections with different lithologies and a slump folded structure identified within sand and silt layer in the third profile. These faults and fractured zones have two explanations; one is being a very good area for transmitting groundwater to the main aquifer. They could be at the same time as a passage for percolating contaminated materials and leakages too, coming into contact with groundwater table with time, especially in profiles one and three because they are within the contamination activity and under the great threat for soil too.

\section{Conclusions}

Based on qualitative and quantitative interpretation of the resistivity data, and constructing 2D section by applying Pichgen and Habibullaev (1985) method for three geo-electrical sections in the study area, the following conclusions can be outlined.

1. The presence of a basin and successions distributed alternatively with variable lithology and thickness, vertically and horizontally. The successive layers of these rocks represent the coarsening upward due to 
progression processes. This alternation reflects the Bai Hassan formation which is characterized by vertical and lateral variations with good quality of groundwater.

2. Seven layers have been outlined in the study area; these layers are:

- First layer is a thin surface layer occurs in all profiles representing the top soil with resistivity range of $28-421 \Omega \mathrm{m}$ and thickness range of $0.25-6.19 \mathrm{~m}$. The variations in resistivity values are due to various types of materials including fine and medium grained material of sand and gravel.

- The second layer has a resistivity range of $20.3-50.0 \Omega \mathrm{m}$ and thickness range of 22.0-49.0 m, comprising fine grained sediments such as silt and sand.

- Third layer has a resistivity range of 35.8-99.2 $\Omega \mathrm{m}$ and a thickness range of 8.0-69.0 m comprising sand and gravel.

- Fourth layer has a resistivity range of $11.0-50.0 \Omega \mathrm{m}$ and a thickness range of 1.0-33.0 m, comprising sand, silt and clay forming an aquifer for groundwater in profile $\mathrm{C}-\mathrm{C}^{-}$.

- Fifth layer has a resistivity range of 50.0-322.0 $\mathrm{m}$ and a thickness range 6.0-41.0 m, comprising a mixture of gravel, sand, silt and clay.

- The sixth geo-electrical layer of the first profile has a resistivity

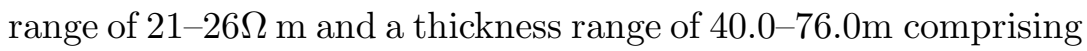
sand, silt and clay, and characterized by intense fracturing by many faults in all studied profiles.

- The seventh layer has a resistivity range of $10.2-61.0 \Omega \mathrm{m}$ comprising silt and clay saturated with groundwater in profiles $\mathrm{A}-\mathrm{A}^{-}$ and $\mathrm{B}^{-\mathrm{B}^{-}}$with a lens composed of mixed gravel, sand, silt and clay and has a resistivity of $61 \Omega \mathrm{m}$. The thickness of this layer is not defined since it is the last layer.

3. The septic tank discharges valley has contaminating the soil but no adverse impact on ground water quality is anticipated in the present project. From the results of geo-electrical sections, the contaminated area has very low resistivity compared with the surrounding area. The contamination zone is detected in the geo-electrical section along profile 
$\mathrm{A}-\mathrm{A}^{-}$in the region where household septic tanks are discharged. The thickness of this zone is about $1.0-1.5 \mathrm{~m}$ with resistivity range of 3.0$4.0 \Omega \mathrm{m}$. In the profile $\mathrm{C}-\mathrm{C}^{-}$a lens is found within the second layer with a resistivity of $2 \Omega \mathrm{m}$ and a thickness of $4 \mathrm{~m}$.

4. The detected groundwater tables begins with a sand and clay layer which represents the fifth layer in the first and second geo-electrical sections; while it is composed of sand and silt layer in third section. The average depth from the surface to the top of the aquifer is about $80 \mathrm{~m}$.

5. The application of Pichgen and Habibullaev (1985) method played an important role in this study by providing subsurface structures and detecting the exact position, dip and direction of faults and detecting groundwater level. 18 faults have been detected in the study area; most of them are located within the third layer of sand and silt with different lengths and almost at the same direction.

6. A small scale slump folding has been identified within sand and silt layer in the third profile, directly under VES19, which is detected by NHP in Pichgen and Habibullaev section.

7. Based on the points of non-homogeneity (PNH), two buried paleochannels have been identified, which are very dominant in the Bai Hassan Formation. One of them is in the first geo-electrical section and the other is in the third geo-electrical section with different lithologies.

8. Four areas of fractured bodies have been detected as results of Pichgen and Habibullaev interpretation in all sections, due to their effect by tectonic activity within the second and third layers in general.

9. The faults and fractured bodies have a strong disadvantage for percolating contaminations and leakages down reaching the groundwater table in the future in both profiles one and three; however it is still a good aquifer for water.

Acknowledgements. The first author would like to thank Professor Ibrahim Othman, the General Director of Atomic Energy Commission of Syria, for allowing the second author (Professor Jamal Asfahani) to participate in this research. Professor Asfahani has generously shared his experience and thoughts with me throughout this research work to whom I am grateful. 


\section{References}

Al-Ane J. M. T., 1983: Application of Electrical Resistivity Method for Hydrogeological Problems in Jolak River Basin. Unpublished M.Sc. Thesis, Baghdad University, Iraq, 133 p. (In Arabic).

Al-Ansari N. A., Essaid H. I., Salim Y. N., 1981: Water resources in Iraq. J. Geol. Soc. Iraq, 14, 1, 35-42.

Al-Fares W., Asfahani J., 2018: Evaluation of the leakage origin in Abu Baara earthen dam using electrical resistivity tomography, northwestern Syria. Geofís. Intl., 57, 223-237.

Arshad M., Cheema J. M., Ahmed S., 2007: Determination of lithology and groundwater quality using electrical resistivity survey. Int. J. Agric. Biol., 9, 1, 143-146.

Asfahani J., 2010: Geophysical case study of shallow and deep structures based on traditional and modified interpretation methods: Application to tectonic studies and mineral exploration. Exploration and Mining Geology, 19, 3-4, 135-152.

Asfahani J., 2011: The Role of Geoelectrical DC Methods in Determining the Subsurface Tectonics Features. Case Studies from Syria, Tectonics, Damien Closson (Ed.), ISBN: 978-953-307-545-7, InTech, Available online: https://www.intechopen.com/ books/tectonics/the-role-of-geoelectrical-dc-methods-in-determining-the -subsurface-tectonics-features-case-studies-f, doi: 10.5772/13580.

Asfahani J., Radwan Y., 2007: Tectonic evolution and hydrogeological characteristics of Khanaser Valley, Northern Syria, derived from the interpretation of vertical electrical soundings. Pure Appl. Geophys., 164, 11, 2291-2311, doi : 10.1007/s00024-007 $-0274-8$.

Asfahani J., Mohamad R., 2002: Geoelectrical Investigation for sulfur prospecting in Techreen structure in northern Syria. Exploration and Mining Geology, 11, 1-4, 49-59, doi: 10.2113/11.1-4.49.

Asfahani J., Radwan Y., Layyous I., 2010: Integrated Geophysical and Morphotectonic Survey of the Impact of Ghab Extensional Tectonics on the Qastoon Dam, Northwestern Syria. Pure Appl. Geophys., 167, 3, 323-338, doi : 10.1007/s00024-009-00 $19-y$.

Bobachev A. B., Modin I. N., Shevnin V. A., 2001: IPI2Win Software - user's manual, ver. 2.1. Moscow State University, GeoScan-M Ltd, 25 pp.

Buday T., 1980: The regional geology of Iraq, Vol 1: Stratigraphy and Paleogeography. Publications of Geological Survey of Iraq, Baghdad, 445 p.

Edwards L. S., 1977: A modified pseudosection for resistivity and IP. Geophysics, 42, 5, 1020-1036, doi: 10.1190/1.1440762.

El-Sayed H. M., 2010: Environmental investigation on Lake Maryut, west of Alexandria, Egypt: geochemical, geophysical and remote sensing studies, M.Sc. Thesis. Alexandria University, Egypt.

Fouad S. F., 2010: Tectonic Map of Iraq, scale 1:1,000,000, 3rd ed. GEOSURV, Baghdad, Iraq. 
Gardi S. Q. S, 2017: Integrated Use of Geoelectrical Resistivity and Geochemical Analysis to Assess the Environmental Impact on Soil and Groundwater at Erbil Dumpsite, West of Erbil City - Iraqi Kurdistan Region. ARO-The Scientific Journal of Koya University 5, 2, 19-31.

Ghaib F. A., 2001: Geophysical Study of the Erbil and Aqra Plains and their Geological Implications. Unpublished Ph.D. Thesis, Salahaddin University, Erbil, 195 p.

Ghaib F. A., Aziz B. K, 2002: A Combination of Electrical Resistivity and Gravity Measurements for Groundwater Prospection in parts of Erbil City. Journal of Duhok University, 6, 1, 105-111.

Gregory M. R., 1969: Sedimentary features and penecontemporaneous slumping in the Waitemata Group, Whangaparaoa Peninsula, North Auckland, New Zealand. New Zeal. J. Geol. Geoph., 12, 248-282, doi: 10.1080/00288306.1969.10420236.

Habib H. R., Al-Saigh N. H., Hassan Z. M., 1990: Geochemistry of under groundwater in Erbil City, Iraq. Mosul, Iraq: Mosul University, 173-188.

Hassan E. O., 1998: Urban Hydrogeology of Erbil City Region. Unpublished Ph.D. Thesis, University of Baghdad, Iraq.

Jassim S. Z., Goff J. C., 2006: Geology of Iraq. Published by Dolin, Prague and Moravian Museum, Brno, 341 p.

Kirsch R., 2006: Grounwater Geophysics. A Tool for Hydrogeology. Springer Berlin Heidelberg New York, 493p.

Majeed R. A., Ahmad M. A., 2002: Brief References on Hydrogeological Characters of Erbil Basin. Unpublished Report.

Oghenekohwo F. O., 2008: A comparison of Resistivity and Electromagnetics as Geophysical Techniques. Postgraduate Diploma, 27 p.

Olasehinde P. I., Ejepu S. J., Alabi A. A., 2013: Fracture Detection in a Hard Rock Terrain Using Geoelectric Sounding Techniques. Water Resources Journal, 23, 1-2, $1-19$.

Pichgin N. I., Habibullaev I. K. H., 1985: Methodological Recomendations in studying geo-tectonic conditions of vertical electrical soundings data with application of EC computer for solving hydrogeological and geo-engineering problems, Tashkend (in Russian).

Reynolds J. M., 2011: An Introduction to Applied and Environmental Geophysics. WileyBlackwell, 698 p.

Sissakian V., 2013: Geological evolution of the Iraqi Mesopotamia Foredeep, inner platform and near surroundings of the Arabian Plate. J. Asian Earth Sci., 72, 152-163, doi : 10.1016/j.jseaes.2012.09.032.

Sissakian V. K., 1997: Geological Map of Iraq. 1st edition, Scale 1:250000, Geosurv., Baghdad, Iraq.

Stevanovic Z., Iurkiewicz A., 2009: Groundwater management in Northern Iraq. Hydrogeol. J., 17, 2, 367-378, doi: 10.1007/s10040-008-0331-0.

Van Loon A. J., 2009: Soft-sediment deformation structures in siliciclastic sediments: an overview. Geologos, 15, 1, 3-55. 
Zohdy A. A. R., Bisdorf R. J., 1989: Schlumberger Sounding Data processing and Interpretation program U. S. Geological Survey, Denver.

Zohdy A. A. R., Eaton G. P., Mabey D. R., 1984: Applications of Surface Geophysics to Groundwater Investigations. Department of Interior U. S. Geological Survey, 3rd Printing. Washington, 116 p., doi: 10.3133/twri02D1. 